\title{
Method for generating non-circular gear with addendum modification and its application in transplanting mechanism
}

\author{
Maile Zhou ${ }^{1,2}$, Yuchao Yang ${ }^{2}$, Mingxu Wei ${ }^{2}$, Daqing Yin ${ }^{2,3 *}$ \\ (1. School of Agricultural Engineering, Jiangsu University, Zhenjiang 212013, China; \\ 2. College of Engineering, Northeast Agricultural University, Harbin 150030, China; \\ 3. Key Laboratory of Modern Agricultural Equipment Technology in Northern Cold Region, Harbin 150030, China)
}

\begin{abstract}
With a focus on the design of tooth profiles of non-circular gears with addendum modifications that conform to the given complex transmission ratio curves and based on a series of discrete point sets on the pitch curves, the criteria for tooth profile distortion and undercut in non-circular gears were proposed. With the constraint of no tooth profile distortion and undercut, the addendum modification coefficient was introduced into the calculation of the distorted and undercut segments of the tooth profile of a non-circular gear, and the addendum modification coefficient of each contact point of the non-circular gear was obtained. Based on the generating principle for gear shaping with gear cutters, a theoretical model for calculating the tooth profile of non-circular gears with addendum modification was derived. The cutting and radial feeding motions of the pinion cutter were ignored, and only the meshing motion was considered. The involute tooth profiles of the pinion cutter enveloped the tooth profile of the non-circular gear. 3D automatic non-circular gear model generation software was developed, which was a secondary development product of the software UG. A non-circular gear in a rice potted seedling transplanting mechanism was designed, and the transplanter was developed and tested. The test results showed that the designed tooth profile of non-circular gear achieved the variable transmission ratios required by the transplanting mechanism. When the transplanting efficiencies were 140 plants/min, 160 plants/min and 180 plants/min, the transplanter completed the rice potted seedling transplanting operation with high quality.
\end{abstract}

Keywords: non-circular gear; tooth profile generation; addendum modification coefficient; enveloping characteristics; transplanting mechanism

DOI: $10.25165 /$ j.ijabe.20201306.5659

Citation: Zhou M L, Yang Y C, Wei M X, Yin D Q. Method for generating non-circular gear with addendum modification and its application in transplanting mechanism. Int J Agric \& Biol Eng, 2020; 13(6): 68-75.

\section{Introduction}

A non-circular gear pair can transmit variable rotations between two shafts. Compared with the slideway mechanism or the rod mechanism, it has the advantages of smooth transmission and a compact structure. It has a wide range of applications in agricultural machinery, textile machinery and in industries such as the aerospace industry ${ }^{[1-4]}$. The rotary transplanting mechanism uses a non-circular planetary gear train system for variable transmission. The system can replace the rod mechanism or slideway mechanism after optimal design and thus greatly reduce the vibration of the equipment and improve the efficiency. It can also meet the trajectory and attitude requirements of the mechanism ${ }^{[5-8]}$. Each tooth of a non-circular gear has a different profile. Further, the two sides of the same tooth also have distinct profiles, which makes the design and manufacture of the non-circular gear difficult. With the development of information technology, computers are increasingly used in the design of

Received date: 2020-01-08 Accepted date: 2020-08-27

Biographies: Maile Zhou, $\mathrm{PhD}$, Lecturer, research interests: design and application of agricultural machinery, Email: zhoumaile@126.com; Yuchao Yang, Master candidate, research interests: transplanting equipment, Email: yangyc8@126.com; Mingxu Wei, Master candidate, research interests: transplanting equipment, Email: 1112233456987@163.com.

*Corresponding author: Daqing Yin, $\mathrm{PhD}$, Associate Professor, research interests: design and application of agricultural machinery. College of Engineering, Northeast Agricultural University, Harbin 150030, China. Tel: +86-045155190971, Email: 63900962@qq.com. non-circular gear tooth profiles, and the level of optimal design of non-circular gears has been significantly improved.

At present, the non-circular gear tooth profile generation methods mainly include the tooth profile conversion method, the envelope characteristic method and the analytical equation-based calculation method. The tooth profile conversion method is simple and easy to understand, and scholars have conducted many studies of this method. Zhang et al. ${ }^{[9]}$ obtained the elliptical gear tooth profile by making non-circular gears equivalent to multiple circular gears with different pitch radii. Liu et al. ${ }^{[10]}$ designed a Pascal gear by dividing its pitch curve into equal-length segments and replaced the non-circular gear tooth profile of each segment with an involute profile of a circular gear. Wang et al. ${ }^{[11]}$ plotted the tooth profile of a non-circular gear with a logarithmic spiral pitch curve and concluded that the profiles of all the teeth are involutes when the number of converted teeth is greater than 41 . The tooth profile conversion method uses the method of equivalency, so there is a certain error between the converted tooth profile and the theoretical tooth profile. In the envelope characteristic method, the non-circular gear tooth profile is enveloped by the gear tooth profiles of rack cutter or gear cutter. Wang et al. ${ }^{[12]}$ enveloped the elliptical gear tooth profile with the tooth profiles of a rack cutter by translating and rotating the rack cutter. Shi et al. ${ }^{[13]}$ proposed a method of enveloping the tooth profile of non-circular gears with one tooth of a gear cutter at an equal arc length. $\mathrm{Yu}$ et al. ${ }^{[14]}$ proposed a concave-convex non-circular gear mechanism with a two-unequal-amplitude transmission ratio function and its tooth profile generation method. 
Wu et al. ${ }^{[15]}$ established a motion model between a rack-shaped cutter and a non-circular rack, proposed a method of sequentially extracting the envelope points of the tooth profile and designed a non-circular gear of a rice planter based on the fully convex pitch curve. Bair ${ }^{[16-18]}$ took the geometric center of the ellipse as the rotation center and established a numerical calculation model of elliptical gears based on the generating principle. Zheng et al. ${ }^{[19,20]}$ proposed a tooth profile generation method for non-circular gears based on envelope characteristics and introduced the envelope models of rack cutters and gear cutters. The envelope characteristic method can control the accuracy of the non-circular gear tooth profile by adjusting the number of envelopes. The method of enveloping a non-circular gear tooth profile with a rack cutter is only applicable to non-circular gears with a fully convex pitch curve, and the method of enveloping a non-circular gear tooth profile with a gear cutter can be applied to non-circular gears with a convex or concave pitch curve. The analytical equation calculation method is a method of obtaining the tooth profile data of non-circular gears by deriving and solving tooth profile equations. Liu et al. ${ }^{[21]}$ deduced the analytical equation of the tooth profile of elliptical gears by dividing the pitch curve equally. The analytical equation calculation method involves complicated equations and a heavy computational burden. There are other methods to generate the tooth profile of non-circular gears. For example, Adel et al. ${ }^{[22]}$ used multiple circular gears with different pitch radii to shift between different gear ratios and obtained an irregular gear pair with an average gear ratio of 1 ; during the meshing process of this kind of irregular gear, the sudden change in the gear ratio is associated with an impact load, so they can only be used in low-speed working environments. $\mathrm{Li}$ et al. ${ }^{[23]}$ proposed a method for solving the non-circular gear tooth profile using the normal isometric family curves of the pitch curve and the tooth profile of the shaper cutter and quantified the degree of tooth undercut of non-circular gears. This method can be used to inspect and evaluate tooth undercut of non-circular gears. To achieve variable transmission rotation between two shafts, there must be a change in the radius of curvature of the non-circular gear pitch curve, which results in concave and convex segments at different positions of the pitch curve of the same non-circular gear. Tooth profile distortion may occur in the concave segments, and undercut may occur in the convex segments. Such a phenomenon has not been reported in the literature.

This research proposed a theoretical model for the numerical calculation of non-circular gear shaping. This model simulates the generation process of non-circular gears using a gear cutter by assuming pure rolling contact between the pitch circle of the gear cutter and the pitch curve of the non-circular gear. In addition, the cutting motion and radial feeding motion were ignored, and only the meshing motion of the gear cutter was considered. The tooth profile of the gear cutter enveloped the tooth profile of the non-circular gear ${ }^{[24]}$. The model only requires a series of point sets on the pitch curve of the non-circular gear (the point sets are approximately evenly distributed on the pitch curve of the non-circular gear) to determine its tooth profile ${ }^{[25]}$.

This research also proposed a method to obtain the non-circular gear pitch curve by fitting control points and applied this pitch curve optimal design method to the optimal design of a rotary potted seedling transplanting mechanism, which successfully solved the difficulties in the development of rotary transplant equipment. This method can theoretically realize the pitch curve design of non-circular gears with any transmission ratio. When the required variable transmission ratios have a wide range and the characteristics of the variable transmission are obvious, the non-circular gear pitch curve will have numerous changes. Multiple convex and concave segments may simultaneously be present on the same pitch curve, and the radii of curvature on different contact points vary greatly. When the radius of curvature is less than the lower limit, tooth profile distortion or undercut will occur, resulting in weakened tooth strength and reduced contact ratio ${ }^{[26]}$. In this research, the introduction of the addendum modification coefficient in the generation of the tooth profile of a non-circular gear effectively reduced the occurrence of tooth profile distortion and undercut. In the theoretical model for the numerical calculation of non-circular gears with the addendum modification, it is assumed that the non-circular gears do not move and that the gear cutter "revolves" around the center of rotation of the non-circular gear while "rotating" around its own center. The distance between the gear cutter and the center of rotation of the non-circular gear is determined by the polar radius and the addendum modification coefficient of the non-circular gear pitch curve. The tooth profile of the non-circular gear is enveloped by a series of tooth profiles from the gear cutter.

\section{Analysis of the pitch curve}

The pitch curve of non-circular gear is obtained by fitting a set of control points. According to the properties of Bezier curve, the first control point and the last control point are overlapped to ensure that the pitch curve is closed. At the same time, the first control point and the last control point are set on the line between the second control point and the penultimate control point to ensure that the pitch curve is smooth. The polygon with the control points as the vertices determines the shape, order and derivative of the pitch curve, as shown in Figure 1. When optimizing the design, a non-circular gear pitch curve with different transmission ratios can be designed by adjusting the relative positions of the control points. After optimizing the design of the non-circular gear pitch curve, the data of a series of points $([r(i), \varphi(i), i=0,1$, $2, \ldots, n])$ on the curve were extracted as the raw data for generating the tooth profile of the non-circular gear with the addendum modification.

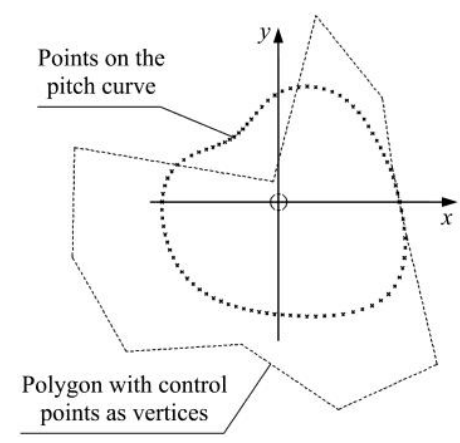

Figure 1 Schematic diagram of the generation of the pitch curve

\subsection{Criteria for tooth profile distortion and undercut}

The different points of the non-circular gear pitch curve have different curvature radii and convex-concave characteristics. When the radius of curvature is positive, the pitch curve is convex; when the radius of curvature is negative, the pitch curve is concave $^{[27]}$. When the radius of curvature of the pitch curve is less than the lower limit, tooth profile distortion or undercut will occur. Tooth profile distortion refers to tooth defects in the non-circular gear caused by the cutting of the tooth root of cutter into the addendum of the non-circular gear. Undercut refers to 
tooth defects in the non-circular gear caused by the cutting of the tooth tip of the cutter into the dedendum of the non-circular gear below the pitch point (Figure 2). Tooth profile distortion can only occur in the concave segment of the pitch curve, and undercut can only appear in the convex segment of the pitch curve.

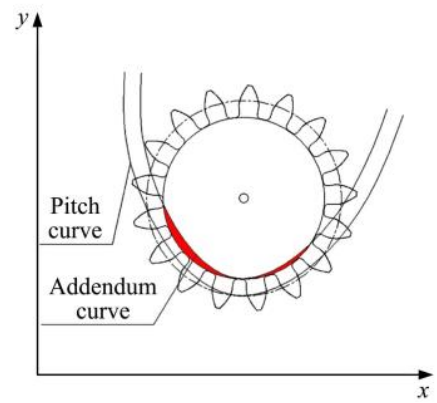

a. Tooth profile distortion

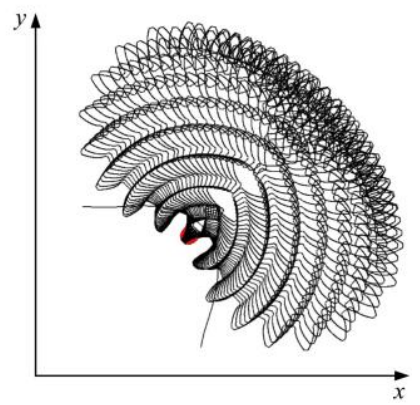

b. Undercut
Figure 2 Schematic diagram of tooth profile distortion and undercut

\subsubsection{Criteria for tooth profile distortion}

Tooth profile distortion will affect the smoothness of non-circular gear transmission, reduce the contact ratio and even result in operational failure of the non-circular gear pair. In the concave segment of the pitch curve, when the pitch circle radius of the cutter is greater than the absolute value of the curvature radius of the non-circular gear pitch curve, tooth profile distortion will occur. If the non-circular gear pitch curve has a negative radius of curvature and the absolute value of the radius of curvature is less than the radius of the pitch circle of the cutter, tooth profile distortion will occur. That is, when $\rho(i)<0$ and $\rho(i) \mid<r_{d}$, the tooth profile is distorted.

\subsubsection{Criteria for undercut}

Undercut will reduce the strength and contact ratio of the teeth. During the generation of the tooth profile, the occurrence of undercut should be avoided to the greatest extent possible. In the convex segment of the pitch curve, when the tooth profile of the cutter interferes with the generated non-circular gear tooth profile, undercut will occur. Undercut occurs if the radius of curvature of

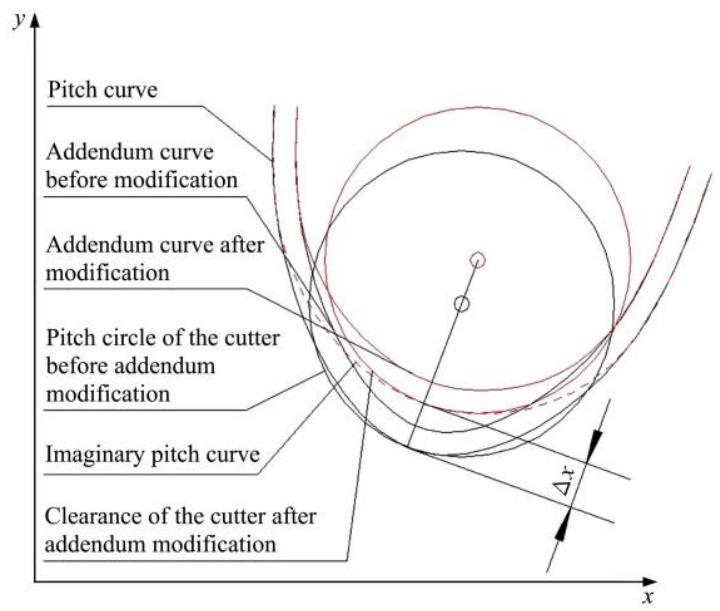

the non-circular gear pitch curve is greater than zero and less than the ratio of the product of the addendum coefficient and the module to the square of the sine of the pressure angle. That is, $\rho(i)>0$ and $\rho(i)<h a^{*} \cdot m / \sin ^{2} \alpha$ lead to undercut.

\subsection{Calculation of the addendum modification coefficient}

Addendum modification is an effective measure to reduce the occurrence of tooth profile distortion or undercut. This research introduced the addendum modification coefficient into the theoretical calculation model of the tooth profile of the non-circular gear and used the addendum modification method at the corresponding positions of the non-circular gear to reduce the occurrence of tooth profile distortion or undercut. The parameters of the non-circular gear are as follows: the number of teeth is $z$, the pressure angle is $\alpha$, the addendum coefficient is $h a^{*}$, the tip clearance coefficient is $c^{*}$ and the average transmission ratio is $N$ (this research takes $N=1$ ).

The addendum modification coefficient of the concave segment of the curve, where tooth profile distortion occurred, is solved as follows (Figure 3):

$$
\left\{\begin{array}{l}
r^{\prime \prime}(i) \times \cos \left[\varphi^{\prime \prime}(i)\right]=r(i) \times \cos [\varphi(i)]+\Delta x(i) \times \cos \left[\mu(i)-\frac{\pi}{2}\right] \\
r^{\prime \prime}(i) \times \sin \left[\varphi^{\prime \prime}(i)\right]=r(i) \times \sin [\varphi(i)]+\Delta x(i) \times \sin \left[\mu(i)-\frac{\pi}{2}\right] \\
\sqrt{\left\{\left[r^{\prime \prime}(i)\right]^{2}+\left[\frac{d r^{\prime \prime}}{d \varphi^{\prime \prime}}(i)\right]^{2}\right]^{3}} /\left\{\left[r^{\prime \prime}(i)\right]^{2}+2 \frac{d r^{\prime \prime}}{d \varphi^{\prime \prime}}(i)-r^{\prime \prime}(i) \times \frac{d^{2} r^{\prime \prime}}{d \varphi^{\prime \prime}}(i)\right\}=r_{d} \\
\frac{d r^{\prime \prime}}{d \varphi^{\prime \prime}}(i)=\frac{r^{\prime \prime}(i)}{\tan \left[\mu(i)-\varphi^{\prime \prime}(i)\right]} \\
\frac{d^{2} r^{\prime \prime}}{d \varphi^{\prime \prime 2}}(i)=\left[\frac{d r^{\prime \prime}}{d \varphi^{\prime \prime}}(i+1)-\frac{d r^{\prime \prime}}{d \varphi^{\prime \prime}}(i-1)\right] /\left[\varphi^{\prime \prime}(i+1)-\varphi^{\prime \prime}(i-1)\right]
\end{array}\right.
$$

where, $\Delta x$ is the distance between pitch circle of gear cutter and pitch curve of non-circular gear, $\mathrm{mm} ; \varphi^{\prime \prime}$ is the polar angle of the meshing point of pitch curve after addendum modification, rad; $r^{\prime \prime}$ is the radial diameter of the meshing point of pitch curve after addendum modification, $\mathrm{mm}$.

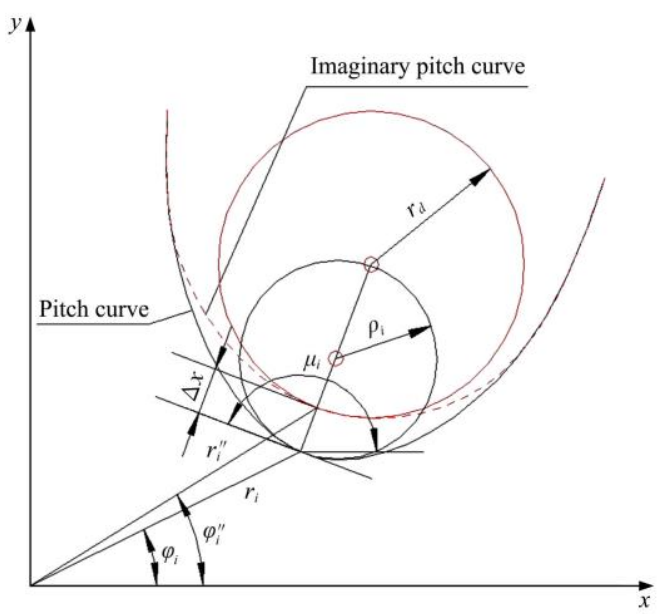

Figure 3 Illustration diagram of tooth profile distortion and addendum modification

According to the generating condition of pitch curve of non-circular gear: $\Delta x\left(i_{0}-1\right)=\Delta x\left(i_{0}\right)=\Delta x\left(i_{n}\right)=\Delta x\left(i_{n}+1\right)=0$, i.e., $\varphi^{\prime \prime}\left(i_{0}-1\right)=\varphi\left(i_{0}-1\right), \varphi^{\prime \prime}\left(i_{0}\right)=\varphi\left(i_{0}\right), \varphi^{\prime \prime}\left(i_{n}\right)=\varphi\left(i_{n}\right), \quad \varphi^{\prime \prime}\left(i_{n}+1\right)=\varphi\left(i_{n}+1\right)$, $r^{\prime \prime}\left(i_{0}-1\right)=r\left(i_{0}-1\right), r^{\prime \prime}\left(i_{0}\right)=r\left(i_{0}\right), r^{\prime \prime}\left(i_{n}\right)=r\left(i_{n}\right)$, and $r^{\prime \prime}\left(i_{n}+1\right)=r\left(i_{n}+1\right)$.

Simultaneously solving the above equations (a total of $5(n+1)+4$ equations, $3(n+1)+2 n+6$ unknowns) yields

$$
\Delta x(i), i=i_{0}-1, i_{0}, \ldots, i_{n}, i_{n}+1
$$

where, $i_{0}$ and $i_{n}$ are the start and end points, respectively, of the segments that are concave on the pitch curve and produce tooth profile distortion.

Therefore, the addendum modification coefficient of the concave segment of the pitch curve that has tooth profile distortion is as follows:

$$
x(i)=\Delta x(i) / m
$$


where, $m$ is the module of the non-circular gear.

The addendum modification coefficient of the convex segment of the pitch curve that is undercut is

$$
x(i)=3\left[h a^{*} \cdot m-\rho(i) \cdot \sin ^{2} \alpha\right] /\left(h a^{*} \cdot m\right)
$$

\section{Theoretical model for numerical calculation of non-circular gear with addendum modification}

In generating the tooth profile for non-circular gears with the addendum modification, based on the generating principle of using a gear cutter and the assumptions of an immobilized non-circular gear and pure rolling of the pitch circle of the cutter along the curve of the non-circular gear, the involute tooth profile of the cutter envelops the tooth profile of the non-circular gear. The accuracy of the tooth profile is controlled by adjusting the envelope times of gear cutter. The more enveloping times, the higher the accuracy of the tooth profile.

\subsection{Calculation of the parameters of non-circular gears with} the addendum modification

It is known that the number of teeth of the non-circular gear is $z$, and the number of teeth of the gear cutter is $z_{d}$ (to reduce the occurrence of tooth profile distortion and undercut, this article takes the number of teeth of the cutter as the minimum number of teeth without undercut, that is, $z_{d}=17$ ).

The module of the non-circular gear is as follows:

$$
m=l /(\pi \cdot z)
$$

where, $l$ is the circumference of the pitch curve of the non-circular gear. $m \cdot z_{d} / 2$.

The radius of the pitch circle radius of the gear cutter is $r_{d}=$

The radius of the addendum circle of the gear cutter tooth is $r_{d a}=m \cdot\left[z_{d}+2\left(h a^{*}+c^{*}\right)\right] / 2$.

The radius of the base circle of the gear cutter tooth is $r_{d b}=$ $m \cdot z_{d} \cdot \cos \alpha / 2$.

The radius of the dedendum circle of the gear cutter tooth is $r_{d f}=m \cdot\left(z_{d}-2 h a^{*}\right) / 2$.

\subsection{Theoretical model for numerical calculations of the driver} gear

The addendum curve (the contour of the tooth blank) is the normal isometric curve of the non-circular gear pitch curve:

$$
\left\{\begin{array}{l}
x_{a}(i)=r(i) \cdot \cos [\varphi(i)]+m \cdot\left[h a^{*}+x(i)\right] \cdot \cos [\mu(i)-\pi / 2] \\
y_{a}(i)=r(i) \cdot \sin [\varphi(i)]+m \cdot\left[h a^{*}+x(i)\right] \cdot \sin [\mu(i)-\pi / 2]
\end{array}\right.
$$

The position of the center of the gear cutter is

$$
\left\{\begin{array}{l}
x o_{d}(i)=r(i) \cdot \cos [\varphi(i)]+\left[m \cdot z_{d} / 2+x(i)\right] \cdot \cos [\mu(i)-\pi / 2] \\
y o_{d}(i)=r(i) \cdot \sin [\varphi(i)]+\left[m \cdot z_{d} / 2+x(i)\right] \cdot \sin [\mu(i)-\pi / 2]
\end{array}\right.
$$

The polar angle at the center of the gear cutter is

$$
\gamma(i)=\varphi(i) \pm \arccos \frac{[r(i)]^{2}+\left[x o_{d}(i)\right]^{2}+\left[y o_{d}(i)\right]^{2}-\left(m \cdot z_{d} / 2\right)^{2}}{2 r(i) \cdot \sqrt{\left[x o_{d}(i)\right]^{2}+\left[y o_{d}(i)\right]^{2}}}
$$

It is negative when $\frac{\mathrm{d} r}{\mathrm{~d} \varphi}(i)>0$ and positive when $\frac{\mathrm{d} r}{\mathrm{~d} \varphi}(i)<0$.

The revolution angle of the gear cutter (the angle of rotation of the line connecting the center of the pitch circle of the gear cutter and the center of rotation of the non-circular gear) is as follows:

$$
\beta(i)=\gamma(\mathrm{i})-\gamma(0)
$$

The angle of rotation of the gear cutter (the angle of pure rolling of the pitch circle of the gear cutter along the pitch curve of the non-circular gear) is as follows:

$$
\alpha(i)=2 l^{\prime} /\left(m \cdot z_{d}\right)
$$

where, $l^{\prime}$ is the arc length of pure rolling of the pitch circle of the gear cutter.

The absolute rotation angle of the gear cutter (the algebraic sum of the revolution angle and the rotation angle) is as follows:

$$
\eta(i)=\alpha(i)+\beta(i)
$$

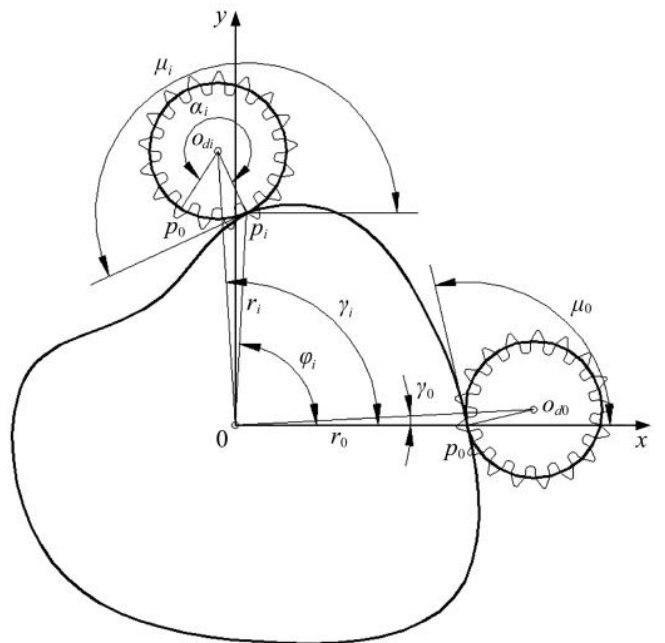

Figure 4 Generation of the theoretical model of the driver gear

\subsection{Theoretical model for numerical calculation of the driven} gear

Assuming that the average transmission ratio of the non-circular gear pair is 1 , the distance between the centers of the non-circular gear pair $O O^{\prime}$ is as follows:

$$
\sum_{i=0}^{n}[\varphi(i)-\varphi(i-1)] \cdot r(i) /\left[O O^{\prime}-r(i)\right]=2 \pi
$$

The radius of the pitch curve of the driven gear is

$$
r^{\prime}(i)=O O^{\prime}-r(i)
$$

The polar angle of the pitch curve of the driven gear

$$
\varphi^{\prime}(i)=\pi-\sum_{j=1}^{i}[\varphi(j)-\varphi(j-1)] \cdot r(j) / r^{\prime}(j)
$$

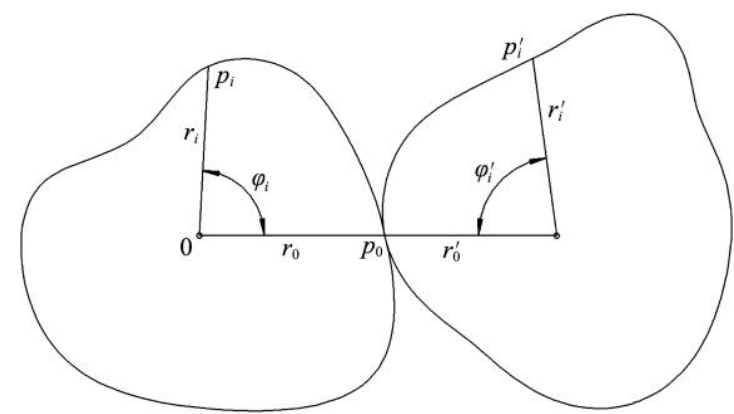

Figure 5 Meshing model of mutually conjugated pitch curves

The addendum curve of the driven gear is

$$
\left\{\begin{array}{l}
x_{a}^{\prime}(i)=r^{\prime}(i) \cdot \cos \left[\varphi^{\prime}(i)\right]+m\left[h a^{*}+x^{\prime}(i)\right] \cdot \cos \left[\mu^{\prime}(i)+\pi / 2\right] \\
y_{a}^{\prime}(i)=r^{\prime}(i) \cdot \sin \left[\varphi^{\prime}(i)\right]+m\left[h a^{*}+x^{\prime}(i)\right] \cdot \sin \left[\mu^{\prime}(i)+\pi / 2\right]
\end{array}\right.
$$

The coordinates of the center of rotation of the gear cutter is

$\left\{x^{\prime} o_{d}(i)=r^{\prime}(i) \cdot \cos \left[\varphi^{\prime}(i)\right]+\left[m \cdot z_{d} / 2+x^{\prime}(i)\right] \cdot \cos \left[\mu^{\prime}(i)+\pi / 2\right]\right.$

$\left\{y^{\prime} o_{d}(i)=r^{\prime}(i) \cdot \sin \left[\varphi^{\prime}(i)\right]+\left[m \cdot z_{d} / 2+x^{\prime}(i)\right] \cdot \sin \left[\mu^{\prime}(i)+\pi / 2\right]\right.$

where, $x^{\prime}(i)=-x(i)$.

The polar angle at the center of the gear cutter is

$$
\gamma^{\prime}(i)=\varphi^{\prime}(i) \pm \arccos \frac{\left[r^{\prime}(i)\right]^{2}+\left[x^{\prime} o_{d}(i)\right]^{2}+\left[y^{\prime} o_{d}(i)\right]^{2}-\left(m \cdot z_{d} / 2\right)^{2}}{2 r^{\prime}(i) \cdot \sqrt{\left[x^{\prime} o_{d}(i)\right]^{2}+\left[y^{\prime} o_{d}(i)\right]^{2}}} ; \text { It }
$$

is negative when $\frac{\mathrm{d} r^{\prime}}{\mathrm{d} \varphi^{\prime}}(i)>0$ and positive when $\frac{\mathrm{d} r^{\prime}}{\mathrm{d} \varphi^{\prime}}<0$.

The revolution angle of the gear cutter is 


$$
\beta^{\prime}(i)=\gamma^{\prime}(0)-\gamma^{\prime}(i)
$$

The rotation angle of the gear cutter is

$$
\alpha^{\prime}(i)=-\alpha(i)
$$

The absolute rotation angle of the gear cutter is

$$
\eta^{\prime}(\mathrm{i})=\alpha^{\prime}(i)+\beta^{\prime}(i)
$$

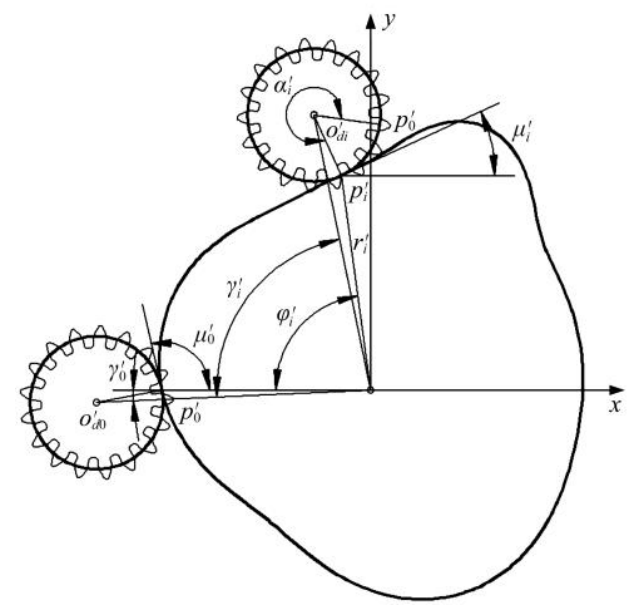

Figure 6 Generation of the model of the driven gear
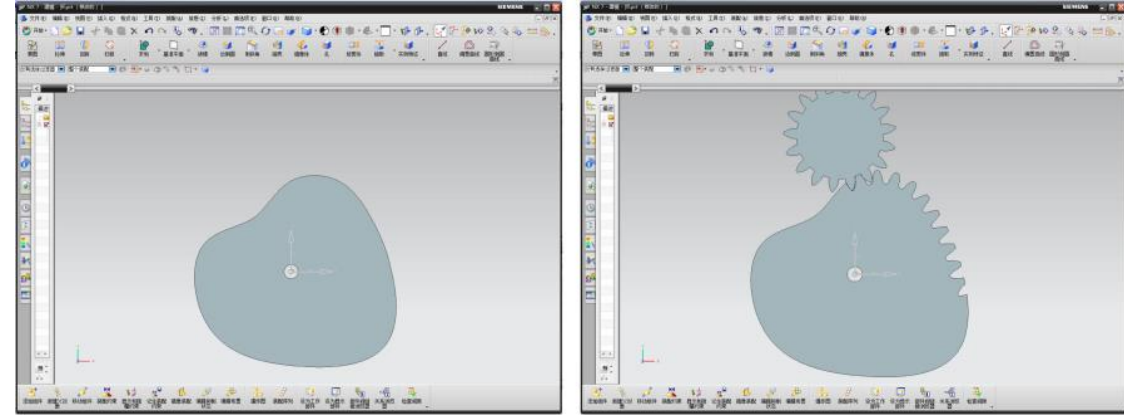

a. Model generation process of the driver gear
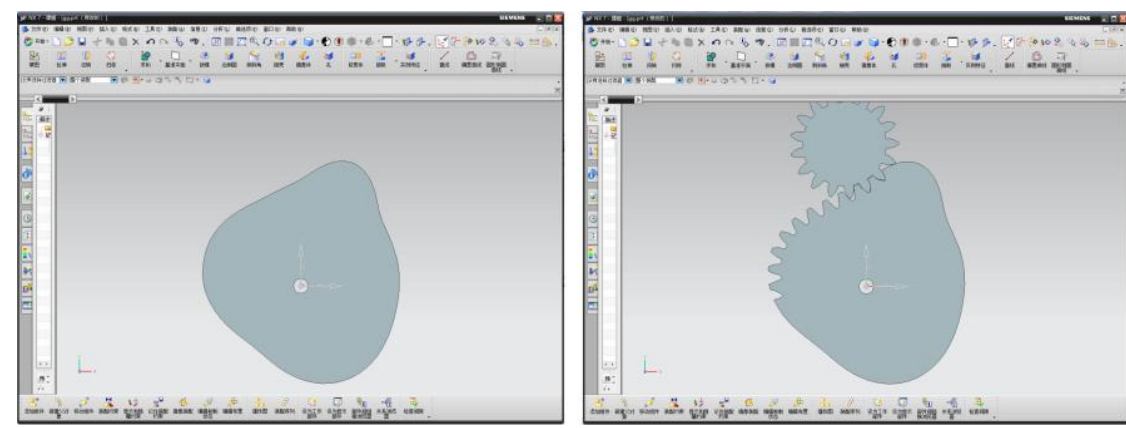

b. Model generation process of the driven gear

\section{Development of 3D model generation software for non-circular gears}

Based on the derived theoretical model of non-circular gears with the addendum modification, this research developed a 3D automatic model generation software for non-circular gears with the addendum modification through the NX/OPEN system and acquired the software copyright. The software can automatically calculate the radius of curvature of the pitch curve of non-circular gear according to the parameters of the non-circular gear given by the designer and determine if the non-circular gear has tooth profile distortion or undercut based on the radius of curvature. If the non-circular gear has tooth profile distortion or undercut, the software automatically calculates the addendum modification coefficient of the pitch curve segments with tooth profile distortion and undercut. The designer only needs to provide a set of points on the pitch curve of the non-circular gear and input the parameters of the non-circular gear (number of teeth, module, pressure angle, addendum coefficient, tip clearance coefficient, etc.). The software then automatically generates a 3D model of the non-circular gear, as shown in Figure 7.

Figure 7 3D model generation process of a non-circular gear

\section{Experimental study}

Transplanting rice potted seedlings requires the transplanting mechanism to complete a specific trajectory and attitude; the key is to achieve complex variable transmission ratios. The rotary rice potted seedling transplanting mechanism uses a K-H-V type non-circular planetary gear train system (as shown in Figure 8), which contains five non-circular gears. However, the non-circular gears used in the transplanting mechanism are difficult to design and manufacture. The design and manufacturing errors cause large changes in the backlash. Some transplanting mechanisms have added auxiliary devices ${ }^{[28,29]}$ to reduce the fluctuation of the backlash. Difficulties in the design of non-circular gears cause problems such as vibration and noise in the transplanting mechanism, which limits the further improvement of the working efficiency of the transplanting mechanism. This research designed non-circular gears for a rotary rice potted seedling transplanting mechanism. For the rotary rice potted seedling transplanting

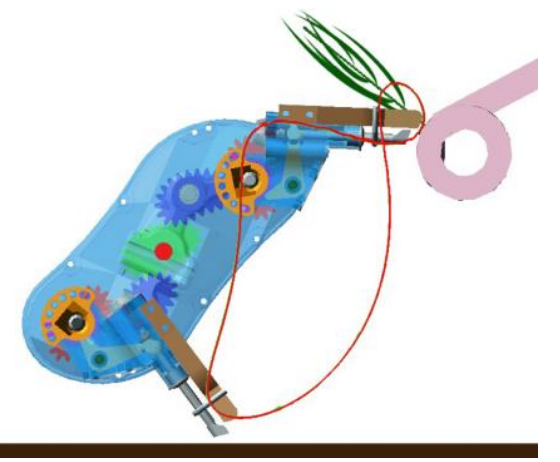

Figure 8 Rice potted seedling transplanting mechanism 
mechanism, the pitch curves of the non-circular gears were obtained by curve fitting, and a series of point sets on the pitch curve were extracted (360 points were selected in this research). The non-circular gear parameters in the rice potted seedling transplanting mechanism as shown in Table 1. $r_{i}$ is the polar diameters of the control points of the pitch curve, and $\theta_{i}$ is the polar angles of the control points of the pitch curve. The non-circular gear parameters shown in Table 2 to design the required non-circular gears using the 3D automatic model generation software developed in this research.

Table 1 Pitch curve parameters

\begin{tabular}{|c|c|c|c|c|c|c|c|c|c|c|c|c|}
\hline Number & 1 & 2 & 3 & 4 & 5 & 6 & 7 & 8 & 9 & 10 & 11 & 12 \\
\hline$r / \mathrm{mm}$ & 12.5 & 27.7 & 49.6 & 48.8 & 58.4 & 47 & 18.2 & 11.9 & 27.7 & 60.5 & 47.8 & 23.7 \\
\hline$\theta /\left(^{\circ}\right)$ & 18.5 & 45 & 75.5 & 104.5 & 131.5 & 165 & 195 & 224.5 & 255.5 & 285 & 316 & 345 \\
\hline
\end{tabular}

Table 2 Non-circular gear parameters

\begin{tabular}{cccc}
\hline Number of gear teeth $(z)$ & Module $(m) / \mathrm{mm}$ & Pressure angle $(\alpha) /\left({ }^{\circ}\right)$ & Addendum coefficient $\left(h a^{*}\right)$ \\
\hline 21 & 2.5753 & 20 & 1 \\
\hline
\end{tabular}

5.1 Calculation of the addendum modification coefficients of the non-circular gears in the transplanting mechanism

The addendum modification coefficient curve of the non-circular gears in the rice potted seedling transplanting mechanism is shown in Figure 9. The calculated polar angles of the pitch curve correspond to the intervals $\left(90^{\circ}, 141^{\circ}\right)$ and $\left(286^{\circ}\right.$, $319^{\circ}$ ). The radius of curvature is less than the lower limit where no tooth profile distortion or undercut occurs. Therefore, the addendum modification coefficient was introduced in the above two intervals, and the maximum addendum modification coefficient was 0.449 .

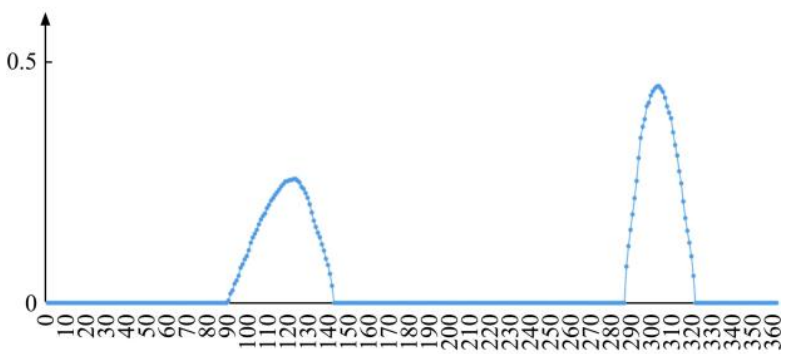

Figure 9 Curve of the addendum modification coefficient

The tooth profiles (Figure 10) of the non-circular gears in the transplanting mechanism were obtained by the non-circular gear numerical calculation model proposed in this research. It can be seen from the figure that the introduction of the addendum modification coefficient can effectively reduce the occurrence of undercut or distortion of the non-circular gear tooth profile and improve the strength of the gear teeth.
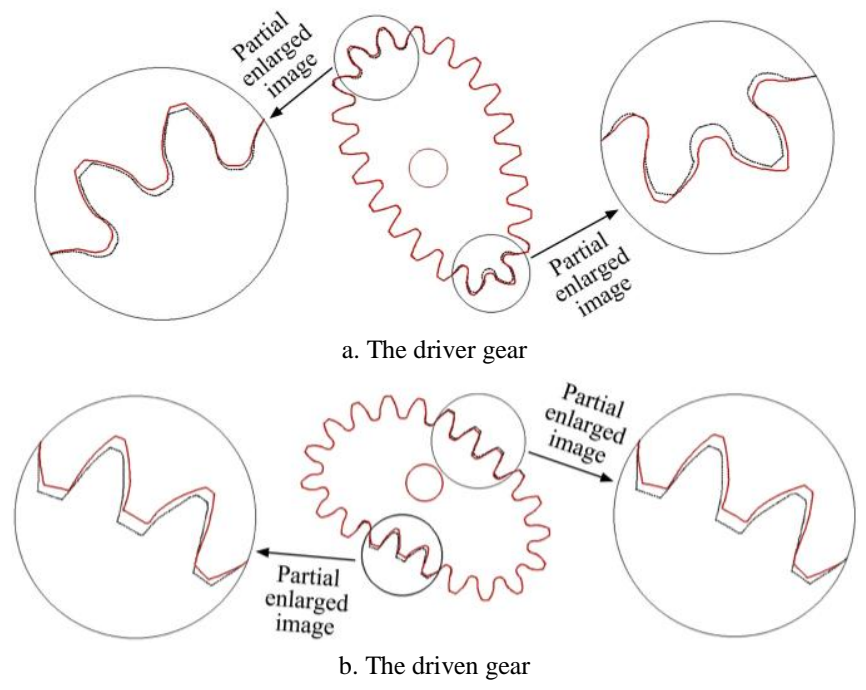

Figure 10 Comparison of tooth profiles of a non-circular gear before and after addendum modification

\subsection{Non-circular gear detection and transplanting test}

Powder metallurgy was used to generate the physical 3D non-circular gears used in the transplanting mechanism, as shown in Figure 11. An iron-copper-carbon alloy with a surface hardness of HRA65-68 and a density greater than $7.0 \mathrm{~g} / \mathrm{cm}^{3}$ was used in the physical model.

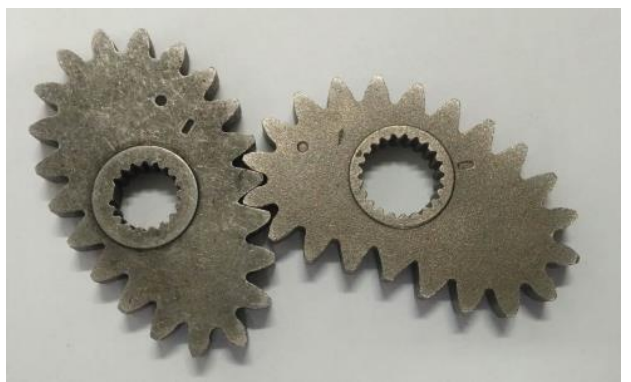

Figure 11 Physical model of the non-circular gears

3D scanning technology was used to carry out reverse detection of the non-circular gears and to verify the consistency between the physical model and the digital model. In this research, the hexagon (romer) scanner is used to detect the non-circular gear, and the highest detection accuracy can reach $17 \mu \mathrm{m}$. By detection, the deviation of the tooth profile between the physical model and the digital model was within $\pm 0.1 \mathrm{~mm}$ (the red color indicates that the physical size is greater than the design size, the blue color indicates that the physical size is less than the design size and the green color indicates that the size is within the deviation range), as shown in Figure 12.

\subsection{Field transplantation experiment}

The non-circular gear generation method proposed in this research was used to manufacture the non-circular gears required in the rice potted seedling transplanting mechanism. The gears were assembled into a transplanting mechanism prototype, as shown in Figure 13. The rice potted seedling transplanter developed by the author is a six-row high-speed transplanter. Each row corresponds to a transplanting mechanism (including five non-circular gears). The field transplantation experiment is shown in Figure 14. The cultivar used for the test was Nennong No.6. The seedlings had an age of 38 days and an average plant height of $120 \mathrm{~mm}$. The average potted seedling loss rate was $2.46 \%$, the mud depth of the paddy soil was $150 \mathrm{~mm}$ and the plant spacing was $200 \mathrm{~mm}$. The experimental results in Table 3 indicate that the designed non-circular gears met the requirements of the variable transmission ratios of the rice potted seedling transplanter. The transmission is stable and reliable. The transplanter can complete the processes of picking, conveying and planting during the transplantation of rice potted seedlings. 


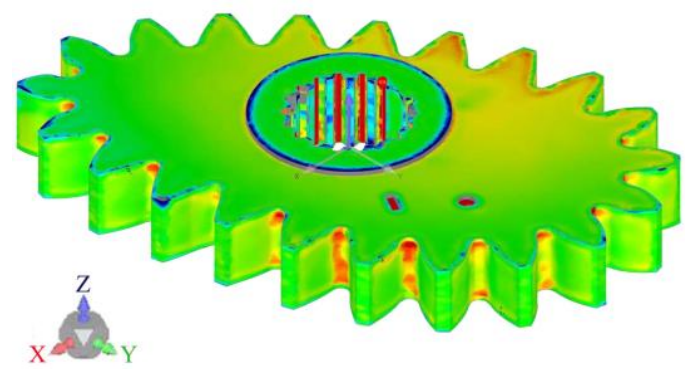

a. Driver gear

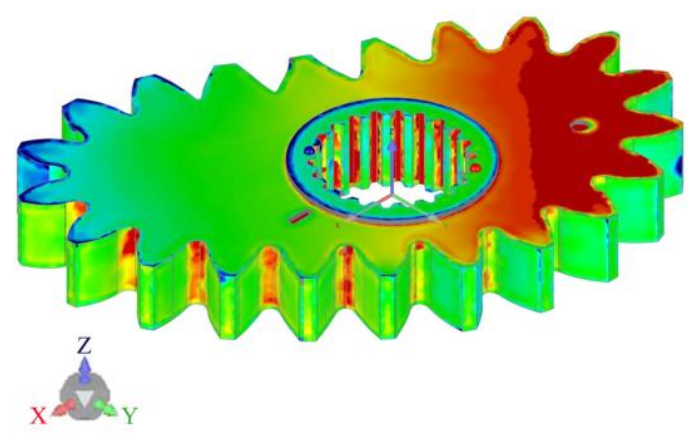

b. Driven gear

Figure 12 Cloud diagrams of the reverse inspection process for the non-circular gears

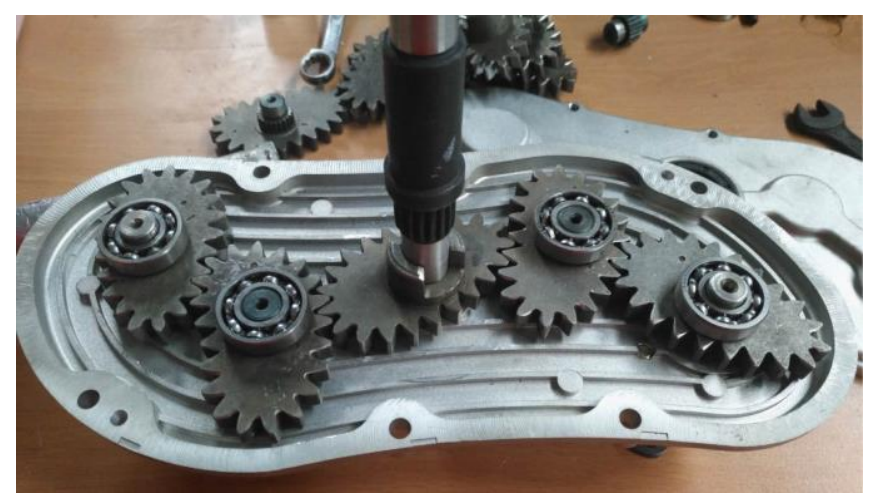

Figure 13 Photograph of the transplanting mechanism assembly

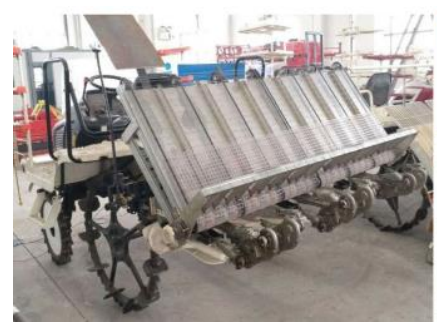

a. Rice transplanter

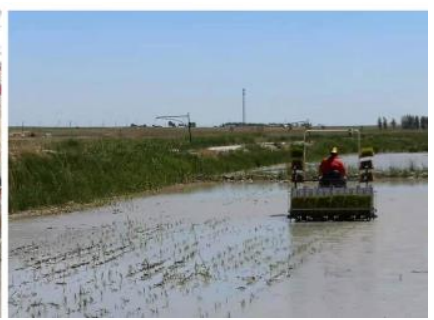

b. Field test
Figure 14 Rice transplanter and field test

Table 3 Field transplantation test results

\begin{tabular}{cccc}
$\begin{array}{c}\text { Transplanting efficiency } \\
\text { /plants } \cdot \text { min }^{-1}\end{array}$ & $\begin{array}{c}\text { Falling rate } \\
/ \%\end{array}$ & $\begin{array}{c}\text { Missing rate } \\
/ \%\end{array}$ & $\begin{array}{c}\text { Seedling injury rate } \\
/ \%\end{array}$ \\
\hline 140 & 2.6 & 3.3 & 0.06 \\
160 & 3.7 & 4.7 & 1.1 \\
180 & 6.7 & 5.5 & 1.2 \\
\hline
\end{tabular}

\section{Conclusions}

According to the generating principle of non-circular gears using the gear cutter, a method of enveloping the tooth profiles of non-circular gears by the involute tooth profile of a gear cutter was proposed. With this method, the generation of tooth profiles for non-circular gears is no longer limited by the criterion of a fully convex pitch curve. Further, this method provides technical support for the design of non-circular gear tooth profiles and promotes the research and application of non-circular gears.

The criteria for tooth profile distortion and undercut of the concave and convex segments of the pitch curve were derived, and the occurrence of tooth profile distortion and undercut were reduced by the addendum modification. The introduction of different addendum modification coefficients at different contact points improves the tooth strength of non-circular gears with complex variable transmission patterns and increases the contact ratio.

A set of points on the pitch curve of the non-circular gear was used as the known data to derive the theoretical model for the numerical calculation of the non-circular gear. This model only considers the meshing motion of the gear cutter and envelopes the non-circular gear tooth profile with the tooth profile of the gear cutter. In theory, this model can generate the tooth profile of non-circular gears with any transmission ratio pattern and thus provides a theoretical basis for the design of non-circular gears.

3D automatic model generation software was developed for non-circular gears. The software can automatically generate $3 \mathrm{D}$ digital models of non-circular gears and their conjugated gears, provide theoretical data for manufacturing non-circular gears and shorten the design cycle of non-circular gears.

A trial production of non-circular gears was completed for rice potted seedling transplanting mechanism with a K-H-V type non-circular planetary gear train system. Through 3D scanning technology, 3D reverse detection was performed on the physical model, and the deviation between the physical model and the digital model was within $\pm 0.1 \mathrm{~mm}$.

The field transplantation experiment was completed using the rotary rice potted seedling transplanting mechanism. The experimental results show that the non-circular gear generation method proposed in this research can realize the design of non-circular gears. The designed non-circular gears met the variable transmission ratios required for the transplantation of rice potted seedlings, verifying the feasibility of the proposed non-circular gear generation method.

\section{Acknowledgements}

This research was financially supported by the National Key Research and Development Program of China (Grant No. 2017YFD070800); the Key Research and Development Program of Jiangsu Province (Grant No. BE2018324); and the Opening of Key Laboratory of Modern Agricultural Equipment Technology in Northern Cold Region (Grant No. KF18-04).

\section{[References]}

[1] Ye J, Chen J N, Zhao X, Sun X C, Xia X D, Gao Q F. Design and applications of generalized eccentric noncircular gears. China Mechanical Engineering, 2018; 29(5): 565-571. (in Chinese)

[2] Quintero Riaza H F, Cardona Foix S, Jordi Nebot L. The synthesis of an $\mathrm{N}$-Lobe noncircular gear using Bezier and B-Spline nonparametric curves in the design of its displacement law. Journal of Mechanical Design, 2007:981-985. 
[3] Chen Y Q, Li W C, Zhang J, Xu Y. Modeling and kinematics simulation of non-circular gear. Mechanical Engineer, 2016; 11: 19-21. (in Chinese)

[4] Wang J, Fan J M, Feng Y. Research on meshing principle and active design method of uniform-variable gear drive. Journal of Mechanical Transmission, 2019; 43(9): 9-13. (in Chinese)

[5] Sun L, Shen J H, Zhou Y Z, Ye Z Z, Yu G H, Wu C Y. Design of non-circular gear linkage combination driving type vegetable pot seedling transplanting mechanism. Transactions of the CSAE, 2019; 35(10): 26-33. (in Chinese)

[6] Bae K Y, Yang Y S. Design of a non-circular planetary-gear-train system to generate an optimal trajectory in a rice transplanter[J]. Journal of Engineering Design, 2007, 18(4):361-372.

[7] Ye B L, Yi W M, Yu G H, Gao Y, Zhao X. Optimization design and test of rice plug seedling transplanting mechanism of planetary gear train with incomplete eccentric circular gear and non-circular gears. Int J Agric \& Biol Eng, 2017; 10(6): 43-55.

[8] Yin D Q, Wang J Z, Zhang S, Zhang N Y, Zhou M L. Optimization design and experiments of a rotary-extensile type flowerpot seedling transplanting mechanism. Int J Agric \& Biol Eng, 2019; 12(6): 45-50.

[9] Zhang M, Kong D Y, Zhao J L, Liu Y P, Hu C B. Solid modeling methods and wire-cutting process simulation of non-circular gears. Applied Mechanics and Materials, 2011; 86: 730-734.

[10] Liu Y P, Wang P, Xian X L, Zhang S Y. Design of the tooth profile of pascal curve gear. Journal of Mechanical Transmission, 2015; 39(3): 50-52.

[11] Wang P, Liu Y P, He G P. Drawing of enclosed non-circular gear tooth profiled based on conversion method of tooth profile. Journal of Mechanical Transmission, 2014; 38(8): 74-76. (in Chinese)

[12] Wang H C, Liu J. Tooth profile design and kinematic mechanism simulation of higher-order elliptic gears based on MAPLE. Journal of Applied Sciences, 2014; 14(4): 362-367. (in Chinese)

[13] Shi Y, Wang S Z. Research on numerical algorithm of non-circular gear's tooth profile. Mechanical Science and Technology for Aerospace Engineering, 2013; 32(8): 1130-1133. (in Chinese)

[14] Yu G H, Yu J P, Tong J H, Ye B L, Zheng S Y. Design of a conjugate concave non-circular gear mechanism. China Mechanical Engineering, 2016; 27(16): 2155-2159, 2165. (in Chinese)

[15] Wu C Y, Jin Y Z, He L Y. Numerical algorithm of tooth profile of noncircular gear based on the characteristics of cutter envelope. China
Mechanical Engineering, 2008; 19(15): 1796-1799. (in Chinese)

[16] Bair B-W. Computer aided design of elliptical gears. Journal of Mechanical Design, 2002; 124(4): 787-793.

[17] Bair B-W. Computer aided design of elliptical gears with circular-arc teeth. Mechanism and Machine Theory, 2004; 39(2): 153-168.

[18] Bair B-W. Computer aided design of non-standard elliptical gear drives Journal of Mechanical Engineering Science, 2002; 216(4): 473-482.

[19] Zheng F Y, Cheng D F, Liu Y Y. A generic algorithm of non- circular gear tooth profile. Journal of Mechanical Transmission, 2013; 37(4): 64-66. (in Chinese)

[20] Zheng F Y, Cheng D F, Liu Y Y. A generic algorithm of non-circular bevel gear tooth profile. Journal of Mechanical Transmission, 2013; 37(5): 57-59. (in Chinese)

[21] Liu Y P, Wang P, Li J. Design the elliptical gear tooth profile via analytical method. Machinery Design and Manufacture, 2015; 5: 214-216.

[22] Al-Sabeeh A K. Irregular gears for cyclic speed variation. Mechanism and Machine Theory, 1991; 26(2): 171-183.

[23] Li J G, Wu X T, Li Z X. Analysis of tooth undercutting in noncircular gears based on numerical computation model of shaping. Transactions of the CSAM, 2007; 38(6): 138-142. (in Chinese)

[24] Zhao Y. Analysis and synthesis of agricultural machinery. Beijing: China Machine Press, 2008. (in Chinese)

[25] Zhou M L, Sun L, Du X Q, Zhao Y, Xin L. Optimal design and experiment of rice pot seedling transplanting mechanism with planetary Bezier gears. Transactions of the ASABE, 2014; 57(6): 1537-1548.

[26] Li J G, Wu X T, Mao S M, He J L. Numerical computation of tooth profile of noncircular gear. Journal of Xi' an Jiaotong University, 2005; 1: 75-78. (in Chinese)

[27] Ju F T, Huang Z P. Solution of curvature radius in curvilinear motion. Physics Bulletin, 2010; 1: 73-74.

[28] Wu G H, Yu G H, Xiang X J, Wang L W. Design and test of rice potted-seedling transplanting mechanism with three transplanting arms. Transactions of the CSAE, 2017; 33(15): 15-22. (in Chinese)

[29] Ye B L, Wu G H, Yu G H, Jin X J, Sun L. Optimized design and tests on rice potted seedling transplanting mechanism of planetary gear train with non-circular gears. Transactions of the CSAM, 2016; 48(11): 68-73. (in Chinese) 